\title{
Flow Quality Surveys in the Settling Chamber of the NASA Glenn Icing Research Tunnel (2011 Tests)
}

\author{
Laura E. Steen* and Judith Foss Van Zante ${ }^{\dagger}$ \\ Sierra Lobo, Inc., Cleveland, OH, 44135 \\ Andy P. Broeren ${ }^{\ddagger}$ \\ NASA Glenn Research Center, Cleveland, OH, 44135 \\ and \\ Mark J. Kubiak ${ }^{\S}$ \\ Gilcrest, Cleveland, OH, 44135
}

\begin{abstract}
In 2011, the heat exchanger and refrigeration plant for NASA Glenn Research Center's Icing Research Tunnel (IRT) were upgraded. Flow quality surveys were performed in the settling chamber of the IRT in order to understand the effect that the new heat exchanger had on the flow quality upstream of the spray bars. Measurements were made of the total pressure, static pressure, total temperature, airspeed, and flow angle (pitch and yaw). These measurements were directly compared to measurements taken in 2000 , after the previous heat exchanger was installed. In general, the flow quality appears to have improved with the new heat exchanger.
\end{abstract}

\section{Nomenclature}

$A_{1} \quad$ Cross-sectional area of the settling chamber

$A_{2} \quad$ Cross-sectional area of the test section

$M \quad$ Mach number

$M_{2} \quad$ Mach number in the test section

$P_{S} \quad$ Static Pressure

$P_{T} \quad$ Total Pressure

$R \quad$ Gas constant $\left(1716\right.$ (ft.lbf.) $\left./\left(\operatorname{slug} \cdot{ }^{\circ} \mathrm{R}\right)\right)$

$T_{S} \quad$ Static Temperature

$T_{T} \quad$ Total Temperature

$T_{T V}$ Total Temperature measured at the turning vanes, average of 24 probes

$U$ Freestream Velocity

$U_{1} \quad$ Velocity in the settling chamber

$U_{2} \quad$ Velocity in the test section

a Speed of sound

$\gamma \quad$ Ratio of specific heats (1.4)

$\rho \quad$ Density

$\rho_{1 S} \quad$ Static density in the settling chamber

*AeroMechanical Test Engineer, Test Engineering Services, 21000 Brookpark Road, MS 77-4, AIAA Member

$\dagger$ AeroMechanical Test Engineer, Test Engineering Services, 21000 Brookpark Road, MS 6-8, AIAA Senior Member

¥Aerospace Engineer, Icing Branch, NASA Glenn Research Center, 21000 Brookpark Road, MS 11-2, AIAA Associate Fellow

$\S$ Electrical Test Engineer, Test Engineering Services, 21000 Brookpark Road, MS 11-1 


\section{Introduction}

In order to improve the capabilities and operational efficiency of NASA Glenn Research Center's Icing Research Tunnel, the temperature control system was upgraded in 2011, which included replacing the heat exchanger and upgrading the refrigeration plant. The previous heat exchanger, installed in 1999, had multiple shortcomings that needed to be improved. The old heat exchanger had inadequate flow mixing that degraded cloud uniformity, and it also would accumulate frost-like particles at cold temperatures and high airspeeds, which were then released into the air to possibly impinge onto a test model. The new heat exchanger was designed with a backwards "Z" chevron profile (as viewed through the tunnel walls). This geometry was chosen for multiple reasons, including to help mitigate the ice erosion problem by reducing the face velocity and to help decrease the pressure gradient across the heat exchanger. Photos of the old and new heat exchangers are shown in figure 1. It was expected that the flow quality would degrade compared to the 1999 design, but this was seen as necessary in order to achieve better icing characteristics.

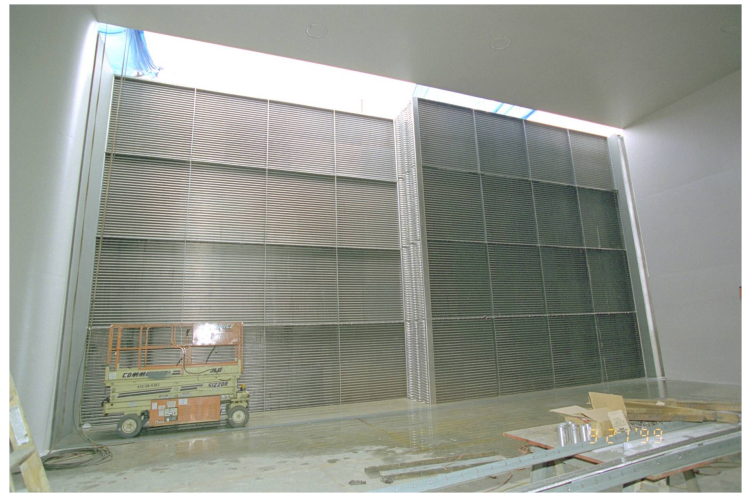

(a) The old heat exchanger, installed in 1999 as two flat exchangers installed nearly side by side.

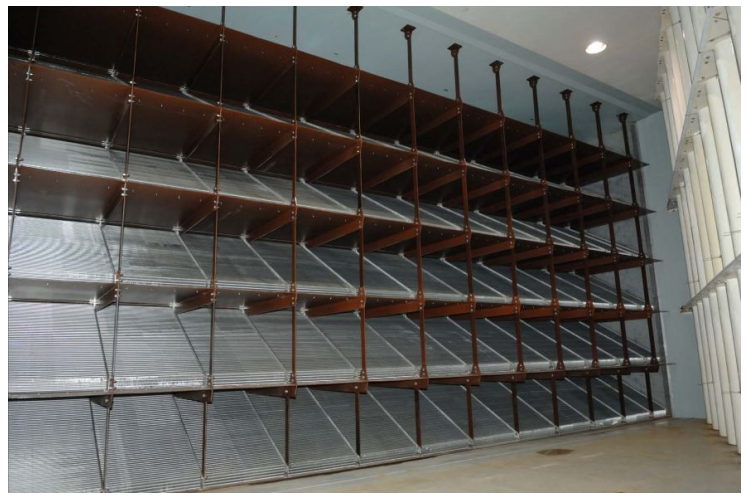

(b) The new heat exchanger, installed in 2011 with a "Z" chevron profile to improve flow mixing.

Figure 1: The old and new heat exchangers.

In order to determine the heat exchanger's effect on the airflow in the Icing Research Tunnel, flow quality surveys were performed in the settling chamber, just upstream of the spraybars. This was done to give a picture of the airflow after it is affected by the heat exchanger and turning vanes, but before it passes across the spraybars and undergoes additional mixing and the addition of water droplets. Additionally, the airflow qualities seen in the settling chamber of any wind tunnel are usually seen in the test section as well. Similar settling-chamber surveys were conducted in 2000 [1]. The tests in 2000 were also conducted after a new heat exchanger was installed, as the original heat exchanger caused large irregularities in the flow. The 2000 tests measured airspeed, total temperature, flow angle, and turbulence intensity. Traversing surveys were performed both upstream and downstream of the heat exchanger using Pitot-static probes, thermocouples, wind-vane anemometers, and hot wires. Overall, the tests showed that the then-new (flat) heat exchanger (seen in figure 1a) greatly improved the flow quality in the settling chamber. Later it was discovered that the flat heat exchanger also had other unacceptable characteristics, including greatly decreased the flow mixing, which degraded the quality of icing cloud. The current tests sought to mimic the previous tests in order to have a good base for comparison.

After the new heat exchanger (figure 1b) was installed in 2011, flow quality surveys were once again performed in the settling chamber of the Icing Research Tunnel, just upstream of the spray bars. Figure 2 shows a partial schematic of the IRT that indicates the survey region that was examined for these tests. These surveys were performed as part of the acceptance test criteria to assess how well the contractor met the requirements in building the new heat exchanger and refrigeration plant. The testing was structured to mimic previous tests in 2000 [1], again, for easier comparison to the data that were taken with the old heat exchanger. The data of primary interest were total pressure and total temperature measurements and the 


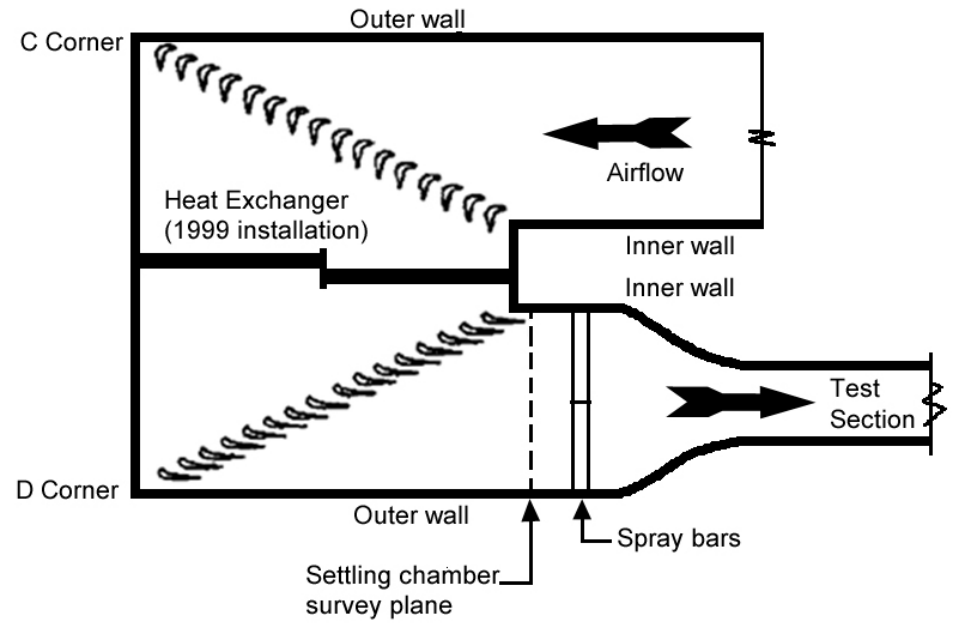

Figure 2: Plan view schematic of IRT 1999 heat exchanger, spray bars, test section, and settling-chamber survey locations.

calculated airspeed. Measurements were also taken of airspeed and flow angle using dual-angle wind-vane anemometers.

These flow quality surveys were just one part of the full calibration of the Icing Research Tunnel that took place after the new heat exchanger was complete and the refrigeration plant was upgraded. Other components of the calibration results are presented elsewhere. Specifically, these include the results of the icing cloud calibration [2] and of the aero-thermal characteristics of the test section [3]. The University of Virginia also contributed to the calibration of the tunnel using three-dimensional Reynold-Average NavierStokes (RANS) simulations on the 2012 configuration of the IRT [4]. Their results were compared to the settling-chamber survey results that are presented in this paper.

\section{Description of Facility}

The Icing Research Tunnel (IRT) is closed-loop, atmospheric wind tunnel that is capable of static air temperatures as low as $-40^{\circ} \mathrm{C}$ and is equipped with spray bars that release liquid water droplets into the air upstream of the contraction, creating an icing cloud that impinges on a model mounted in the test section. Figure 3 shows a schematic of the IRT, updated with the new heat exchanger and refrigeration plant.

Airflow is driven with a 25 -foot diameter, twelve-blade fan that is powered by a 5000-hp electric motor [5]. With an empty test section, the velocity can be controlled between 50 and 350 knots $(591 \mathrm{ft} / \mathrm{s})$. The upgrades to the heat exchanger and refrigeration plant also have resulted in improved temperature control, such that the total air temperature can now be maintained at total temperatures as high as $20^{\circ} \mathrm{C}$. This is particularly necessary for flow quality tests, since the instrumentation that is used is not designed to withstand icing environments.

The settling chamber is in between the turning vanes and the contraction section of the IRT. Surveys were performed just upstream of the icing spray bars. The IRT settling chamber does not contain any flow conditioners such as flow straighteners, as these would accumulate ice and detract from flow mixing, which would greatly degrade the IRT's icing capabilities. Downstream, the contraction ratio is approximately 14 to 1 .

\section{Test Equipment}

In order to be able to easily compare the test results to the previous tests performed in the settling chamber, the test equipment that was used for the 2011 surveys is nearly the same as what was used for the 2000 surveys. The traverse pulley systems were also mounted into the same mounting holes as were used in 2000 . 


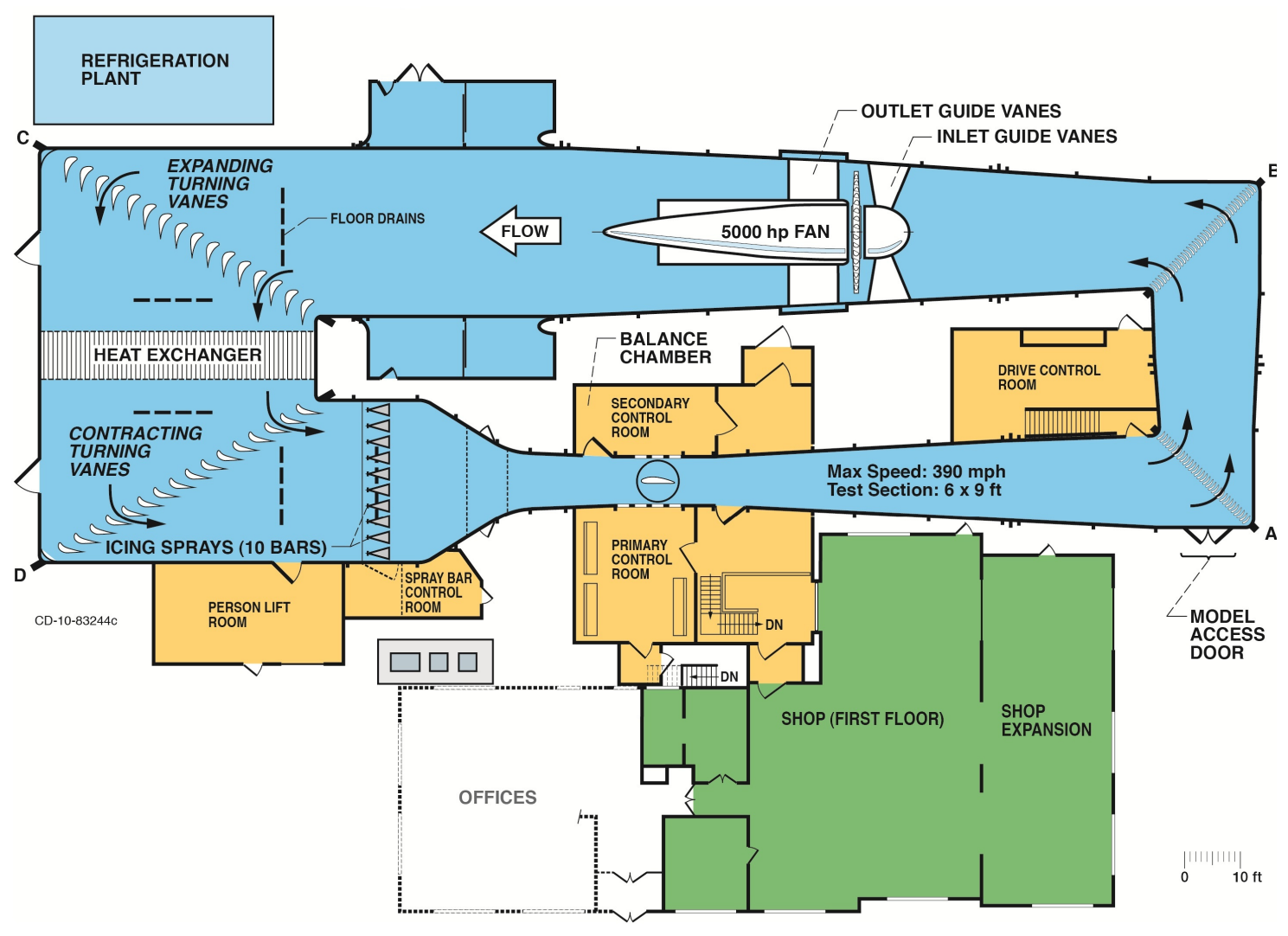

Figure 3: Schematic of the NASA Glenn Research Center Icing Research Tunnel, with upgraded heat exchanger and refrigeration plant.

\section{A. Traversing Platforms}

Two traversing platforms were used, consisting of a square beam that was fitted with a mounting platform on the upstream side. Each shaft was supported by cables at the leading and trailing edges. A close-up of one traversing platform can be seen in figure 4 . The leading edge cable rode on a pulley that was driven by a remotely controlled electric motor system that allowed each platform to traverse a vertical or horizontal profile within the settling chamber. The electric motor drive system accurately measured the position of the platform using absolute encoders for feedback. With this system, the platform position could be accurately and repeatedly measured within 2 inches. A photograph of these traversing platforms in horizontal configuration can be seen in figures 5. Figure 6 also shows the motor and pulley system that were used. The following instrumentation were mounted onto each of the traversing platforms: one Pitot-static probe, one resistance temperature detector total temperature probe (RTD), and one wind-vane anemometer. The Pitot-static probes were used to measure total and differential (total minus static) pressure. The RTDs were used to measure total temperature. The wind-vane anemometers had a propeller that measured airspeed, as well as tail fins coupled to two potentiometers that measured the pitch and yaw angle of the airflow.

\section{B. Instrumentation and Equipment}

The instrumentation used to collect total pressure, static pressure, total temperature, flow angle (pitch and yaw), airspeed, and platform position data are described in this section

Pitot-Static Probes: Each traversing platform included a 9-hole Pitot static probe to measure total pressure and static pressure ${ }^{\mathrm{a}}$. The total pressure was measured using a 0-25 psia transducer. The change in pressure between the total and the static taps was measured using a \pm 1 inches-of-water differential

${ }^{a}$ The flow-angularity taps of these probes were not used because the air velocities in the settling chamber were too low to obtain angularity data of reasonable quality; the probes are not calibrated for such low speeds 


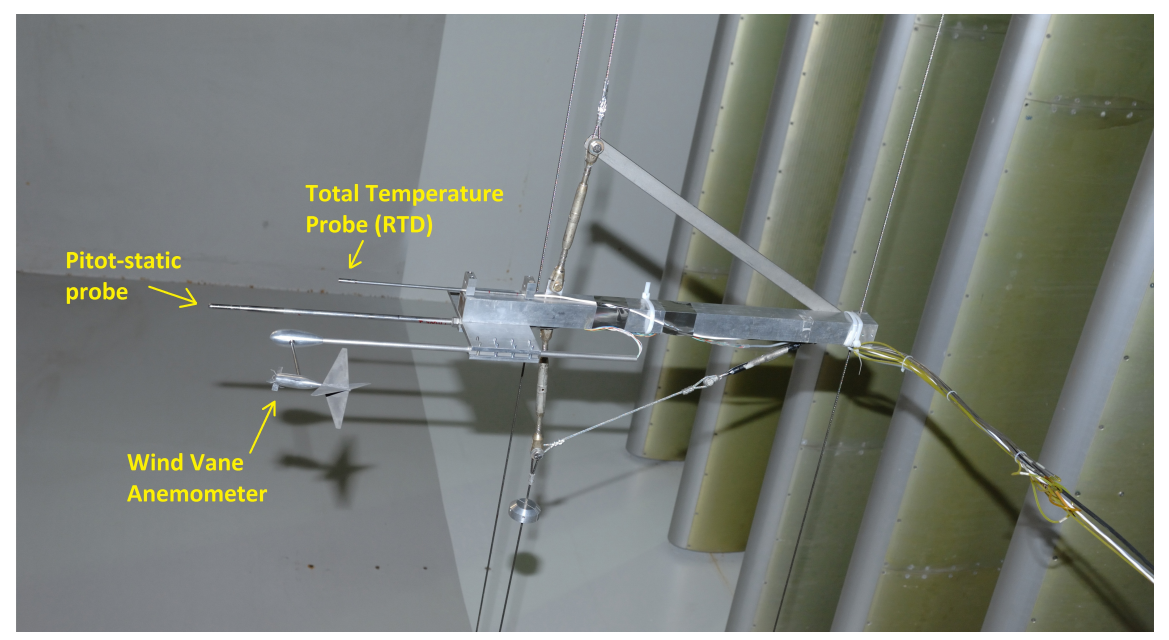

Figure 4: A traversing platform mounted for a horizontal survey (looking up), instrumented with total temperature probe, Pitot-static probe, and wind-vane anemometer. Airflow moves from left to right.

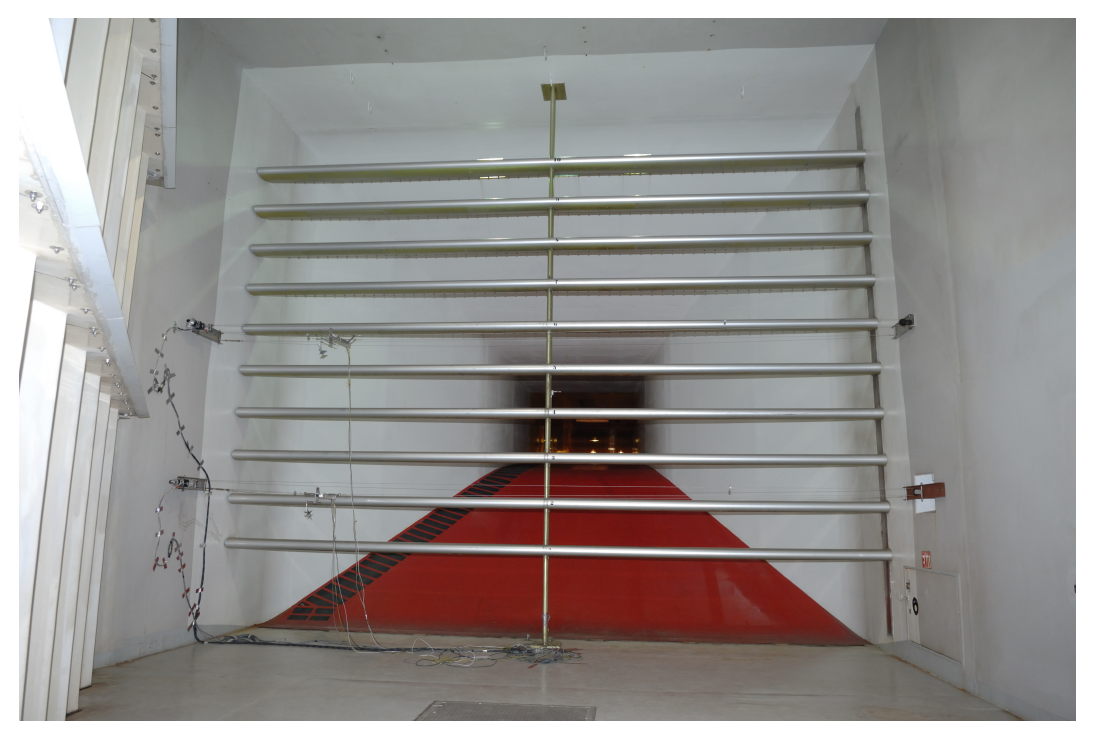

Figure 5: Two traversing platforms mounted for horizontal survey, with spray bars and test section behind.

transducer, and this value was converted and subtracted from the total pressure to provide the static pressure. These transducers were calibrated on site at the GRC calibration lab before testing. The total pressure transducers had a maximum error of \pm 0.02 psia $(0.08 \%)$ and the differential pressure transducers had a maximum error of \pm 0.0011 inches of water.

RTDs: Each traversing platform had a RTD to measure the total temperature. These RTDs were 100ohm platinum and with an exposed tip. The calibrations of both RTDs were completed within a calibrated, high-accuracy thermo-electric temperature controller (dry well) at the IRT before testing. This calibration procedure has been outlined in greater detail by Oldenburg [6]. The RTDs had a maximum error of less than $\pm 0.15{ }^{\circ} \mathrm{C}$. The response time of these RTDs is less than 10 seconds, which was the settling time before every data point.

Wind-Vane Anemometers: Since the air velocity is too low in the settling chamber to measure flow angularity with a 9-hole Pitot-static probe, the flow angularity (pitch and yaw) was measured using dualangle wind-vane anemometers. These anemometers were also capable of measuring airspeed. A picture of these anemometers can be seen in figure 4. Flow angularity is recorded by measuring the voltage across the respective pitch and yaw potentiometers within the anemometer. The airspeed is recorded through the 


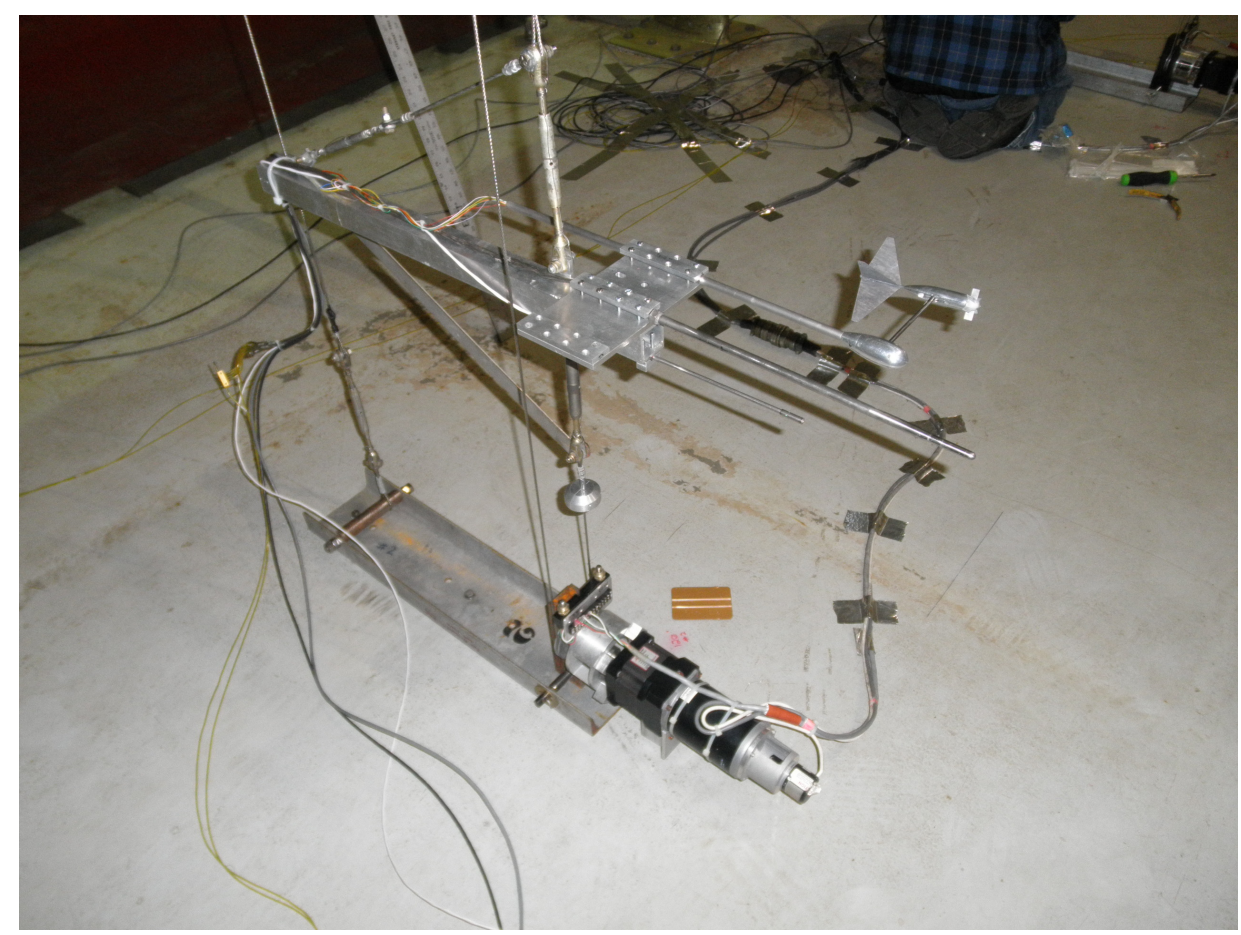

Figure 6: A traversing platform mounted for a vertical survey, fully instrumented and mounted onto cables driven by an electric motor system.

wind-vane propeller, which is read using a frequency-to-voltage signal converter. The same type of windvane anemometers were used for the 2000 tests, although the actual instruments were borrowed from Langley Research Center (LaRC) for these tests. LaRC also provided calibration information for the anemometers. The angle calibration curves were developed by using a mounted protractor system that was specially made at LaRC for these instruments, and the results were compared to previous calibration data taken for these instruments. Additionally, prior to running the surveys, the wind-vane anemometer velocities were tested in one of the free-jet facilities at Glenn Research Center. These tests were used to develop velocity calibration curves and also to determine the angle that the anemometers read when set in a flow angle of zero (airflow on, zero pitch and yaw). This angle reading was factored into the calibration curves as an offset angle.

Probe Actuator Control System (PACS): The PACS was used to control and record the motion and the position of the traversing platforms. The system included the motors, indexer/drive units, rack unit, computer, software, and interface cables for communication with the data acquisition system. The platform position was automatically controlled and measured using the encoder system. This system allowed the test conductor to program a fully-automated survey for each test configuration, which including settling time. The time-averaging of each point was set using the data acquisition system. By fully-automating this setup, the test conductor could focus more greatly on the test as a whole. The PACS also communicated with the data-acquisition system so that data were recorded at the proper time intervals, and the current location of the platform was recorded with the data. Limit switches were also installed on the traverse cables which would send a signal to the PACS when a platform was near one of the tunnel walls. When the signal was received that a limit had been reached, all motion of that platform ceased.

\section{Facility Instrumentation}

Facility instrumentation were also used to measure the flow conditions for the test. Pitot-static probes at the entrance of the test section were used to measure total pressure and to calculate the test section velocity. These Pitot-static probes use a 20 psia total pressure transducer and a 3 psid differential transducer for the total and static measurements. Additionally, 24 RTDs mounted in the settling chamber on the turning vanes were used for the facility's recorded total temperature. Further information about these RTDs, along with their accuracy and calibration, has been given by Oldenburg [6]. The average of these 24 RTDs was 
recorded as the final total temperature. A camera system was also used in the settling chamber to observe the traversing platforms during testing.

\section{Data Acquisition System}

Data Acquisition was all done through an Escort Alpha system, which provided steady-state data acquisition as well as real-time data display. This system is commonly used in the larger facilities at NASA Glenn Research Center. It is capable of reading input from the Electronically Scanned Pressure (ESP) System, inputs from the facility distributed process control system, and inputs from any analog devices such as thermocouples and individual pressure transducers. Readings are scanned at a rate of $1 \mathrm{~Hz}$, and results can be displayed in realtime during testing. Each data point recorded during these tests was a 20-second average (i.e., 20 scans averaged).

\section{Test Matrix}

The surveys were run at a test-section velocity of 300 knots $(350 \mathrm{mph}, 506 \mathrm{ft} / \mathrm{s})$ with an empty test section. This is near the maximum velocity that the IRT is capable of maintaining. Since measurements were conducted in the settling chamber upstream of the contraction section, velocities measured by the traversing platforms were much lower than that of the test section. In order to improve the quality of data, testing was done near the IRT's maximum velocity capability. Previous tests have shown that the loop flow quality does not vary much with test section velocity [7], and so only one velocity was used for this test. This velocity was also chosen because it was used for the tests in 2000. The total temperatures was maintained at $18^{\circ} \mathrm{C} \pm 5^{\circ} \mathrm{C}$, which is at the upper end of the current controllable temperature range in the IRT. It was necessary to test above freezing temperature in order to obtain good data from the instrumentation, and it was also necessary have a controlled temperature to avoid overheating the facility.

Data were collected as the traversing platforms moved from their starting point across the survey region in 3-inch increments until reaching the far end of the survey, and then traversed back to the starting point in 12-inch increments for the return survey. This was done to test repeatability. There was a 10-second delay before each data point to allow settling time.

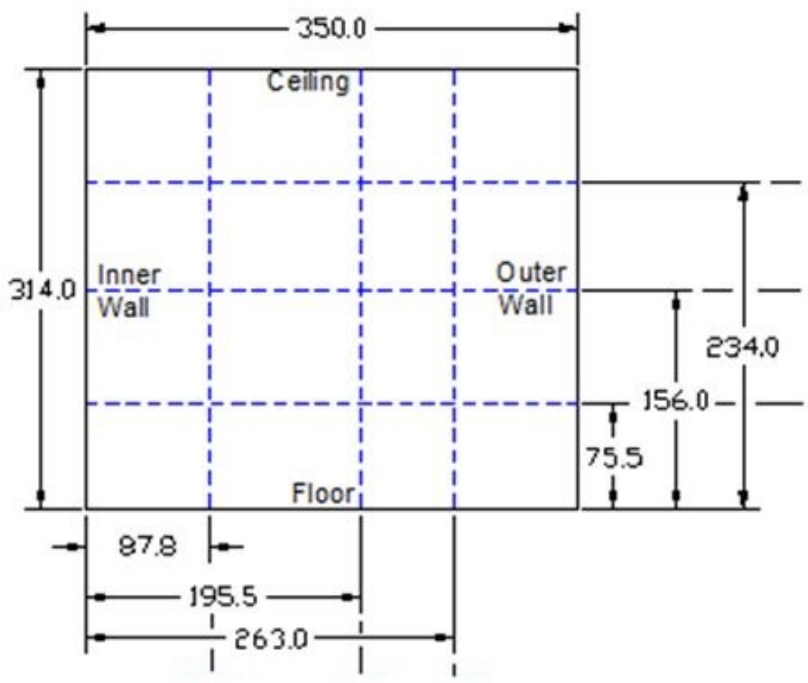

Figure 7: Settling chamber survey locations (facing downstream towards test section).

Surveys were made in three vertical and three horizontal locations, as shown in figure 7 . Since two traversing platforms were used simultaneously, two vertical and two horizontal test configurations were needed to cover these locations. The centerline survey was tested twice to determine repeatability. These four configurations are described as follows: 
1. Vertical surveys at the "centerline" and "outer" locations.

2. Vertical surveys at the "inner" and "centerline" locations.

3. Horizontal surveys at the "ceiling" and "centerline" locations.

4. Horizontal surveys at the "centerline" and "floor" locations.

Here, "inner" refers to the vertical survey location closest to the inner wall of the IRT (north side), "ceiling" refers to the horizontal survey location closest to the ceiling of the IRT, and "outer" and "floor" follow correspondingly. "Centerline" is self-explanatory, although it is still written in quotes because the survey locations are not exactly centered for either the horizontal or vertical surveys. Table 1 shows the test matrix for the settling chamber flow quality surveys conducted in 2011. All surveys were conducted approximately 25 inches upstream of the spraybars.

Table 1: Test Matrix for the October 2011 IRT Settling Chamber Flow Quality Survey Tests.

\begin{tabular}{|c|c|c|c|}
\hline $\begin{array}{c}\text { Platform } \\
\text { Configuration }\end{array}$ & Platform positions & $\begin{array}{c}\text { Test Section } \\
\text { Airspeed (knots) }\end{array}$ & $\begin{array}{c}\text { Tunnel Total } \\
\text { Temperature }\left({ }^{\circ} \mathrm{C}\right)\end{array}$ \\
\hline 1 & Outer, Centerline & 300 & $18 \pm 5$ \\
2 & Centerline, Inner & 300 & $18 \pm 5$ \\
3 & Ceiling, Centerline & 300 & $18 \pm 5$ \\
4 & Centerline, Floor & 300 & $18 \pm 5$ \\
\hline
\end{tabular}

\section{Operational Procedures}

The test engineer provided the facility staff with as much information as was available for installing hardware and completing the test setup to prepare for each test run. The staff was able to determine installation requirements, and thorough checkouts were performed before each test to ensure that the setup would operate as required.

The following are additional procedures that were specific to the settling chamber flow quality survey tests:

1. The test engineer reviewed the test setup with the technicians prior to each run to ensure that all hardware and instrumentation was properly installed.

2. Test runs were performed of the survey hardware while the IRT fan was off to ensure that the system would perform as expected. Practice tests were performed to check for and fix any cable slippage that occurred.

3. The PACS positioning was calibrated before every test to ensure that the traversing platforms were moving the expected distance.

4. Measurements were made of the locations of the instrumentation with respect to the wall and floor.

5. Purge air was run through the Pitot-static probes during tunnel start-up to prevent condensation from building up and skewing data. The purge air was turned off prior to recording data.

6. Detailed notes of the test setup and test execution were maintained in the Engineers Log Notebook.

7. The operation of all instrumentation was checked through the Escort system prior to every run. Online data review continued throughout the run to ensure quality data.

8. Motion of the traversing platforms was observed using a small camera set up upstream in the test chamber. This allowed the test engineers to ensure that the PACS program was executing properly and the instrumentation cabling was not interfering with the traversing platforms. 
9. When changing configurations, the "centerline" traversing platform, as described in section IV, was kept in the centerline position, while the outermore traversing platform was moved from one side to another. In this way, all centerline data were taken using the same instrumentation and hardware, and likewise, all data taken on the "inside", "outside", "floor" or "ceiling" were taken using the same instrumentation.

10. When changing from the vertical configuration to horizontal configurations, the wiring and data collection parameters for the anemometers were changed so that pitch and yaw were still properly recorded even though the platform and instrumentation were rotated $90^{\circ}$.

These surveys were meant to act as a means of comparison to the tests run in 2000, but the heat exchanger was not operational for those tests, and so those were run at ambient temperature. However, the 2011 tests were run in the fall instead of in the middle of winter, and the IRT would overheat too quickly to be able to collect data at ambient temperature. The 2011 tests were run with a fully-operational temperature control system, although an added purpose to running these tests was to give the facility operators practice with the new temperature control system.

\section{Data Reduction and Analysis}

\section{A. Pressure and Airspeed Data}

Pitot-static total pressure and static pressure measurements were taken with the traversing platform primarily to determine the velocity profile just downstream of the heat exchanger. These pressures were used to determine the local Mach number, following the form of equation 1, which is equation 44 in reference [8], for $\gamma=1.4$, where $M$ is Mach number and $P_{T} / P_{S}$ is the ratio of total to static pressure.

$$
M=\sqrt{5\left(\left(\frac{P_{T}}{P_{S}}\right)^{2 / 7}-1\right)}
$$

Velocity $(U)$ is then determined using the definition of Mach number, $M \equiv U / a$. The speed of sound, $a$, is calculated using $a=\sqrt{\gamma R T_{S}}$, where $\gamma=1.4$ and $R=1716$ (ft. $\cdot$ lbf.) $/\left(\right.$ slug $\left.{ }^{\circ} \mathrm{R}\right)$. The static temperature $T_{S}$ in this equation is calculated using equation 43 in reference [8], where once again $\gamma=1.4$, resulting in equation 2 .

$$
T_{S}=\frac{T_{T}}{1+M^{2} / 5}
$$

These equations are then combined to calculate velocity as $U=M \cdot a$.

It should be noted that the Mach number in the settling chamber is very low; $M \approx 0.03$ for these measurements. Therefore, the velocity can be computed more directly using an incompressible flow model. Making the assumption that $T_{T}=T_{S}$ allows the air density to be calculated as:

$$
\rho=\frac{P_{S}}{R T_{T}}
$$

The velocity is then calculated directly from the differential pressure measurement:

$$
U=\sqrt{\frac{2 \Delta P}{\rho}}
$$

Calculations with the experimental data showed that the velocity calculated from each method agreed to within $0.02 \%$, which is essentially identical. The bias uncertainty in the velocity was estimated to be less than $\pm 0.3 \%$ for 20:1 odds using the methods of Kline and McClintock [9] and Coleman and Steele [10].

\section{B. Expected Settling Chamber Velocity}

The measured velocities were also compared to what velocity would be expected in the settling chamber, if no airflow measurements were taken there. This value was estimated based on the continuity equation for quasi-one-dimensional flow, which simplifies to equation 5 where $\rho$ is density, $U$ is velocity, and $A$ is the 
cross-sectional area at the location of measurement. Subscripts 1 and 2 denote the locations of measurement, which in this case are the settling chamber and the test section, respectively.

$$
\rho_{1 S} U_{1} A_{1}=\rho_{2 S} U_{2} A_{2}
$$

Since the velocity in $\mathrm{D}$-corner is so low $(M \approx .03)$, the ratio $\rho_{2 S} / \rho_{1 S}$ can be approximated as the density ratio within the test section, $\rho_{2 S} / \rho_{2 T}$. This ratio is defined in equation 45 of reference [8]. Thus, the expected velocity in the settling chamber is described by equation 6 .

$$
U_{1}=U_{2} \frac{A_{2}}{A_{1}}\left(1+\frac{M_{2}^{2}}{5}\right)^{-5 / 2}
$$

If we assume the test section static temperature is approximately $17^{\circ} \mathrm{C}$, then the test section Mach number is approximately 0.45 . Then we can apply the known contraction ratio $A_{2} / A_{1}$ and test section velocity of $500 \mathrm{ft} / \mathrm{s}$ to find that the expected settling chamber velocity is approximately $32.0 \mathrm{ft} / \mathrm{s}$. Of course, there is additional information that is not taken into account with this value, including the assumptions associated with quasi-one-dimensional flow analysis and effects of boundary layer growth.

\section{Wind Anemometer Data}

The correlations between the angle readings and the voltage output of the wind anemometers were checked using specially machined angle-check hardware that was developed at Langley Research Center and sent to Glenn Research Center. A 5-Volt signal was applied across the pitch and yaw potentiometers, and the feedback voltage was recorded for various angles. Pitch and Yaw angle readouts were measured in 10-degree increments from $-100^{\circ}$ to $100^{\circ}$, with additional measurements at $\pm 5^{\circ}$. The result was a linear correlation between voltage output and pitch or yaw angle, such that,

$$
(\text { Angle })=c_{1} \cdot(\text { Voltage })+c_{0}
$$

where the Voltage is in $\mathrm{mV}$ and the angle is in degrees. The coefficients $c_{1}$ and $c_{0}$ are determined from the linear fit of the calibration.

The angle offset for the anemometers was also adjusted based on tests conducted in the free-jet facility at Glenn Research Center. These tests indicated what angles the wind anemometers measured when placed in zero flow-angle airflow, and these data were applied into the calibration curves by adjusting the zerointercept in the linear calibration curve. These measurements were compared with old calibration data that was received from Langley Research Center, and these were found to agree within $3.3^{\circ}$ for the range that was measured by the anemometers.

The wind-vane anemometer airspeed was calibrated in a free-jet facility at Glenn Research Center, for velocities ranging between 25 and $55 \mathrm{ft} / \mathrm{s}$. The wind-vane anemometers were tested one at a time, and the velocity signal was received through the frequency-to-voltage converter, such that the voltage outputs were calibrated instead of the propellers' rotational frequencies. A sample calibration can be seen in figure 8 . After this velocity calibration, the propeller on one of the wind-vane anemometers broke and needed to be replaced, so in-situ calibrations were also conducted in the settling chamber for three of the four configurations. The Pitot-static probes were used for the reference velocity, and the settling chamber velocities ranged from 24 to $35 \mathrm{ft} / \mathrm{s}$ for these calibrations. In the first (vertical) test configuration, the in situ calibration of both anemometers showed good agreement with the results of the free-jet calibration. The in situ calibrations for the horizontal configurations did not show good agreement and suggested that some part of the instrumentation broke in between calibrations. Thus, the wind-vane anemometer data from the horizontal configurations was not used. The calibration coefficients that were used for the data presented in this paper were obtained from the free-jet facility tests.

\section{Discussion of Results}

The Pitot-static data were of primary importance, since they were used to give the overall indication of how the flow field was affected by the new heat exchanger and to indicate if the contractor had met their design criteria for flow quality downstream of the new heat exchanger. Plots of the velocity profiles are shown in figures 9 and 10. These plots show the velocity as calculated from the Pitot-static probe 
measurements and total temperature probes, compared alongside data taken with the old heat exchanger in 2000. Since the "centerline" surveys were repeated, $9 \mathrm{~b}$ shows the data from both the first and second test. However, during the second vertical centerline survey, some of the transducers needed to be switched and the data suggest that the pressure transducers may have been improperly zeroed. Thus, figure 10b does not include the second centerline trace. This error was fixed before the horizontal surveys were conducted. The vertical surveys in figure 10 also include velocity measurements measured from the wind-vane anemometers, for further comparison of velocity measurements. Wind-vane-anemometer velocity data were omitted from the horizontal surveys. This was because in the horizontal surveys, the in situ calibrations and velocity data trends from the wind-vane anemometers suggested that some part of that instrumentation system broke during the hardware change from the vertical configuration to the horizontal configuration. The cause of this break is currently uncertain. Since the Pitot-static data were of much greater concern, the data discrepancy was not noticed until after the tests were complete.

For a better interpretation of the data in figures 9 and 10, a few things may be noted. First, there may be large spatial variations in velocity near the face of the heat exchanger due to its geometry, and the survey locations close to the inner wall of the IRT are more likely to be affected by these variations. Notice in figure $1 \mathrm{~b}$ that the new heat exchanger is very close to the turning vanes at the inner wall of the IRT. This idea is further discussed later in this paper, in reference to the flow angularity measurements. Second, figure 11 shows the velocities calculated from the Pitot-static probes, normalized by the velocity from the entrance of the test section that was measured with each point. Also in this figure is a basic mapping of the Z-chevron profile of the heat exchanger upstream, as well as the splitters that support the turning vanes just upstream. This helps explain the resulting shape of the Pitot-static velocity profile. The biggest variation in velocity is seen at the wakes of the turning-vane splitters. This is also strongest at the vertical profile $87.8 \mathrm{in}$. from

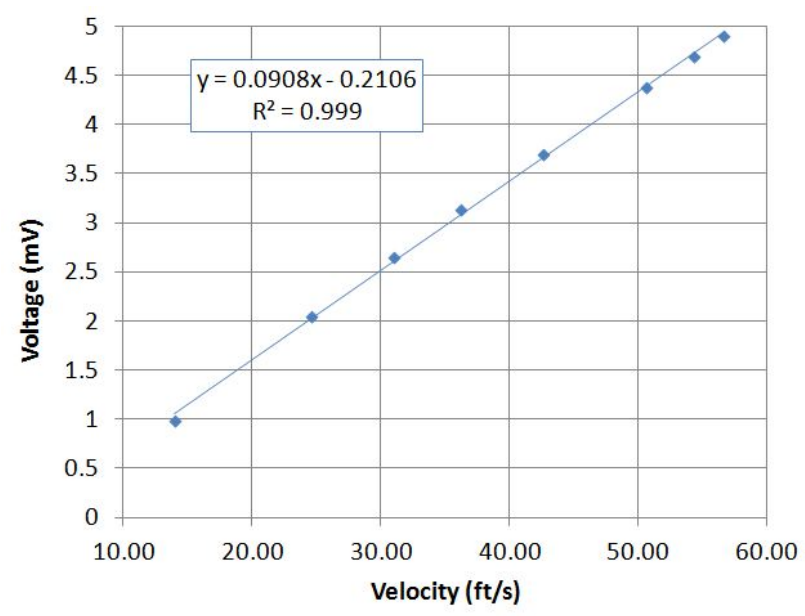

Figure 8: Velocity calibration conducted in a Glenn Research Center free-jet facility, for the wind-vane anemometer that was used at the "centerline" location for all testing configurations. the inner wall, where the traversing platform is the closest to the turning vanes.

Again, the total temperature was controlled to $18 \pm 5^{\circ} \mathrm{C}$ for the 2011 surveys. The settling-chamber surveys were the very first tests that were run in the IRT with the new heat exchanger and refrigeration plant, and the temperature control system was still being perfected. The temperature data from the traversing platforms were used to calculate the velocities from the total and static pressure measured from the Pitotstatic probes. The spatial temperature data from the surveys are not presented in this report because it would give an inadequate picture of the current excellent spatial temperature uniformity. Instead, data are presented that were collected during the aero-thermal calibration that was conducted in January of 2012 by Pastor-Barsi [3]. These data were taken with the previously-mentioned facility RTDs that are mounted on the settling-chamber turning vanes, downstream of the heat exchanger and upstream of the settling-chamber survey locations. Figure 12 shows measurements from these RTDs, indicating the uniformity of the settling chamber for conditions that were closest to the other tests presented here. These data were taken at a test section velocity of 295 knots, with no air from the spray bars, and the average (settling chamber) total temperature was $6.27^{\circ} \mathrm{C}$. The contour plot shows the differences between the measured temperature and the average temperature $\left(T_{T}-T_{T V}\right)$ of all 24 turning-vane RTDs. For this condition, the maximum difference is $0.20^{\circ} \mathrm{C}$ and the minimum difference is $-0.18^{\circ} \mathrm{C}$. The standard deviation of these temperatures is $1.5 \%$ of the mean total temperature.

The flow angles that were recorded by the wind-vane anemometers proved difficult to obtain with great accuracy. The final measurements are presented in figures 13 and 14. As stated before, the angle readouts were checked with specially-machined hardware and compared with calibration data obtained at Langley Research Center in 1999. The attempts that were made to eliminate the angle offset were apparently 
unsuccessful. When the wind-vane anemometers were checked in the free-jet facility, the test engineers recorded what angle the wind anemometers were reading when mounted in the freestream at zero pitch and yaw. This angle was subtracted from the final calculations, but the data still show an apparent angle offset in the results. Examination of figures 13a 13b also make it clear that the offset is consistent between like probes, since the two center surveys were performed with the same wind-vane anemometer, as were the two side surveys. For this reason, the pitch and yaw data should be interpreted to determine the flow angle trends at these survey locations, but not to determine quantitative values for pitch and yaw.

One note of interest was that in the vertical surveys, there is substantially more variation in the yaw angle than in the pitch angle. This was investigated further by presenting the problem Clark, et.al. at the University of Virginia, who are computing some of the flow physics within NASA Glenn's IRT using their Virtual Icing Research Tunnel (VIRT) [4]. Clark et.al. used the geometry of the heat exchanger, turning vanes, and IRT walls to compute the velocity contours at the exit of the heat exchanger, on either side of the settling-chamber turning vanes, and in the settling-chamber survey plane. The results show that the geometry of the heat exchanger causes a large velocity gradient the heat-exchanger exit, as seen in figure 15. This velocity gradient then passes over the turning vanes, as seen in figure 16 . The resulting velocity in the settling-chamber survey plane can be seen in figure 17, showing the $\mathrm{x}-, \mathrm{y}-$, and z-components of the velocity at the location of the settling-chamber surveys. These figures further suggest that the velocity gradients coming off the face of the heat exchanger are continuing past the turning vanes. Figure 16 particularly suggests that the turning vanes turn this velocity gradient into a large variation in spanwise velocity, resulting in large spatial variations in yaw angle. Final comparisons for pitch and yaw angle are shown in figure 18, which shows good prediction of the yaw angles. It is uncertain why the pitch angles in figure 18 do not match trends as closely as the yaw angles. It should be noted that figures $15,16,17$, and 18 were all generated by Clark, et.al. [4] and used with his permission.

\section{Summary of Results}

The modifications that were made to the Icing Research Tunnel heat exchanger and refrigeration plant resulted in overall improvement to the settling chamber airflow.

The standard deviations of the velocity profiles from the new heat exchanger were calculated. The standard deviations from the 2000 data are shown in table 2, and this data may be compared to the results from the 2011 data, shown in table 3. These results were well within acceptance criteria for the new heat exchanger. All standard deviation results improved, with the possible exception of the vertical inner survey. This is probably because that survey location is closest to the turning vanes and heat exchanger.

The repeat surveys showed good repeatability for all Pitot-static and wind-anemometer data. All survey data plots shown in this report had repeatability similar to that of figure 9 .

The temperature survey results could not be included in this report, but the temperature distributions in the settling chamber of the IRT are uniform to within $\pm 1^{\circ} \mathrm{C}$. Data on this has been reported by PastorBarsi [3].

The vertical spatial variations in pitch angle have improved and the vertical spatial variations in yaw angle have degraded. Additional work done by the University of Virginia confirms that the trends in yaw angle can be expected based on the geometry and location of the heat exchanger.

Table 2: Standard deviation results from 2000 Flow-Quality Surveys (old heat exchanger).

\begin{tabular}{|l|c|c|c|}
\hline & $\begin{array}{c}\text { Average } \\
\text { velocity }(\mathrm{ft} / \mathrm{s})\end{array}$ & $\begin{array}{c}\text { Standard } \\
\text { Deviation }(\mathrm{ft} / \mathrm{s})\end{array}$ & $\begin{array}{c}\text { (standard deviation)/ } \\
\text { (average velocity) }\end{array}$ \\
\hline Vertical, inner & 34.7 & 0.95 & $2.5 \%$ \\
Vertical, centerline & 33.7 & 1.34 & $4.0 \%$ \\
Vertical, outer & 32.2 & 0.87 & $2.9 \%$ \\
\hline Horizontal, lower & 34.3 & 1.38 & $4.0 \%$ \\
Horizontal, centerline & 35.2 & 1.19 & $3.4 \%$ \\
Horizontal, upper & 34.0 & 1.10 & $3.2 \%$ \\
\hline
\end{tabular}


Table 3: Standard deviation results from 2011 Flow-Quality Surveys (new heat exchanger).

\begin{tabular}{|l|c|c|c|}
\hline & $\begin{array}{c}\text { Average } \\
\text { velocity }(\mathrm{ft} / \mathrm{s})\end{array}$ & $\begin{array}{c}\text { Standard } \\
\text { Deviation }(\mathrm{ft} / \mathrm{s})\end{array}$ & $\begin{array}{c}\text { (standard deviation)/ } \\
\text { (average velocity) }\end{array}$ \\
\hline Vertical, inner & 32.7 & 0.89 & $2.7 \%$ \\
Vertical, centerline & 32.7 & 0.69 & $2.1 \%$ \\
Vertical, outer & 31.2 & 0.72 & $2.3 \%$ \\
\hline Horizontal, lower & 30.7 & 0.63 & $2.0 \%$ \\
Horizontal, centerline & 33.6 & 0.75 & $2.2 \%$ \\
Horizontal, upper & 30.6 & 0.62 & $2.1 \%$ \\
\hline
\end{tabular}

\section{References}

\footnotetext{
${ }^{1}$ Gonzalez, J. C., Arrington, E. A., and Curry, M. R., "Flow Quality Surveys of the NASA Glenn Icing Research Tunnel (2000 Tests)," NASA, CR-2001-210682, 2001.

${ }^{2}$ Van Zante, J. F., Ide, R. F., and Steen, L. E., "NASA Glenn Icing Research Tunnel: 2011 Cloud Calibration Procedure and Results," 4th AIAA Atmospheric and Space Environments Conference, New Orleans, LA (submitted for publication), June 2012.

${ }^{3}$ Pastor-Barsi, C. M. and Arrington, E. A., "2012 Aero-Thermal Calibration of the NASA Glenn Icing Research Tunnel," 4th AIAA Atmospheric and Space Environments Conference, New Orleans, LA (submitted for publication), June 2012.

${ }^{4}$ Clark, K. M., Malinowski, M., Loth, E., Steen, L. E., Van Zante, J. F., and Ide, R. F., "Air Flow and Liquid Water Concentration Simulations of the 2012 NASA Glenn Icing Research Tunnel," 4th AIAA Atmospheric and Space Environments Conference, New Orleans, LA (submitted for publication), June 2012.

${ }^{5}$ Soeder, R. H., Sheldon, D. W., Ide, R. F., Spera, D. A., and Andracchio, C. R., "NASA Glenn Icing Research Tunnel User Manual," NASA, TM-2003-212004, September 2003.

${ }^{6}$ Oldenburg, J. R., Ide, R. F., Del Roso, R. L., and Murphy, P. J., "Improvements to the NASA Glenn Icing Research Tunnel's Air Temperature Measurement System," 44th AIAA Aerospace Sciences Meeting and Exhibit, Reno, NV, January 2006.

${ }^{7}$ Arrington, E. A., Gonzalez, J. C., and Kee-Bowling, B. A., "Flow Quality Studies of the NASA Glenn Research Center Icing Research Tunnel Circuit (1995 Tests)," NASA, TM-2000-107479, 2001. 1953.

${ }^{8}$ Ames Aeronautical Laboratory Research Staff, "Equations, Tables, and Charts for Compressible Flow," NASA, TP 1135,

${ }^{9}$ Kline, S. and McClintock, F. A., "Describing Uncertainties in Single Sample Experiments," Mechanical Engineering, Vol. 75, No. 1, 1953, pp. 3-8.

${ }^{10}$ Coleman, H. W. and Steele, W. G., Experimentation and Uncertainty Analysis for Engineers, Wiley-Interscience, New York, 1989, pp. 40-118.
} 


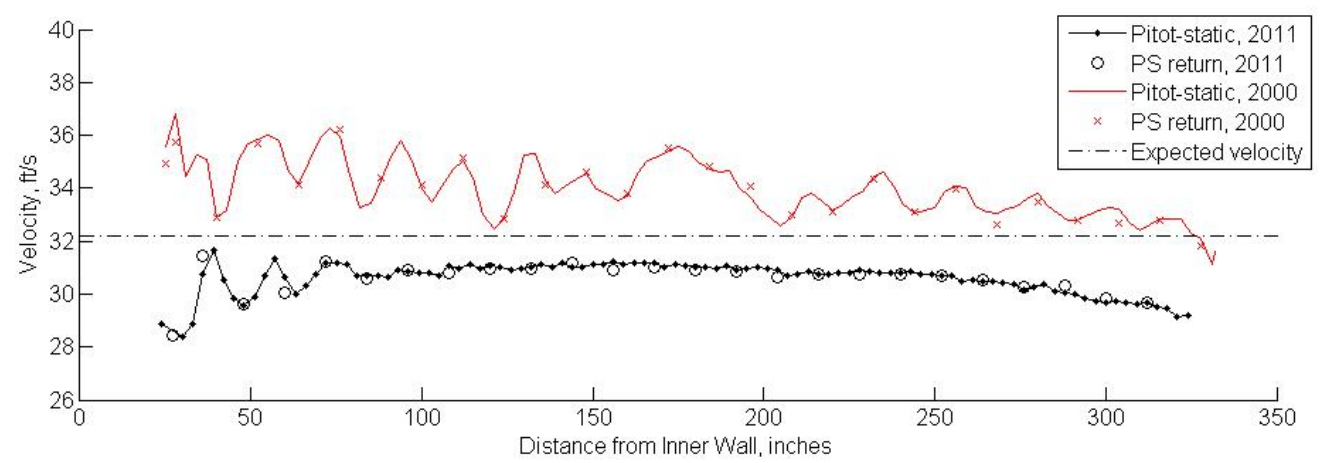

(a) 234.0 inches above the floor

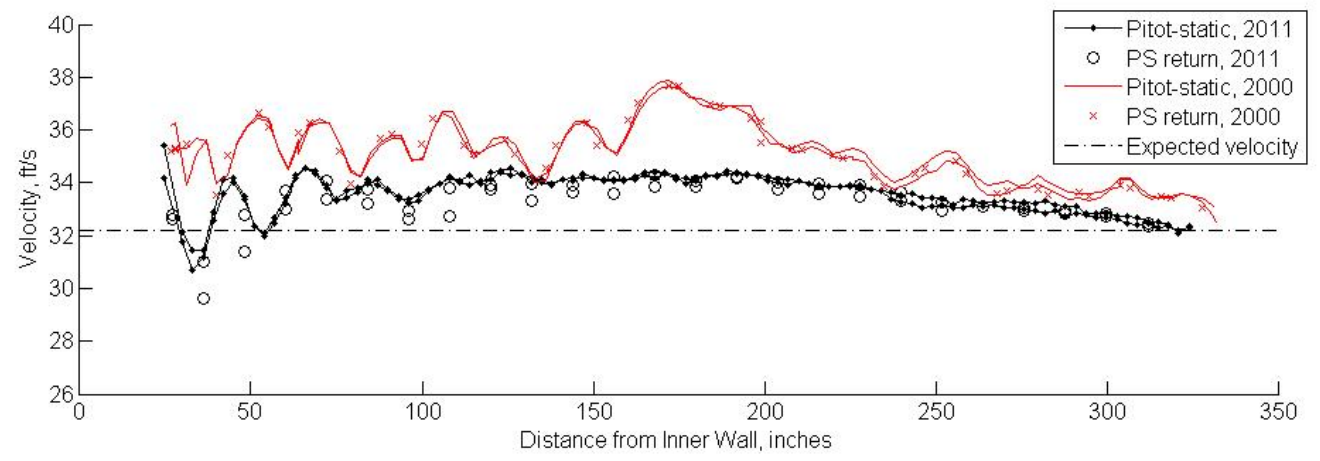

(b) 156.0 inches above the floor

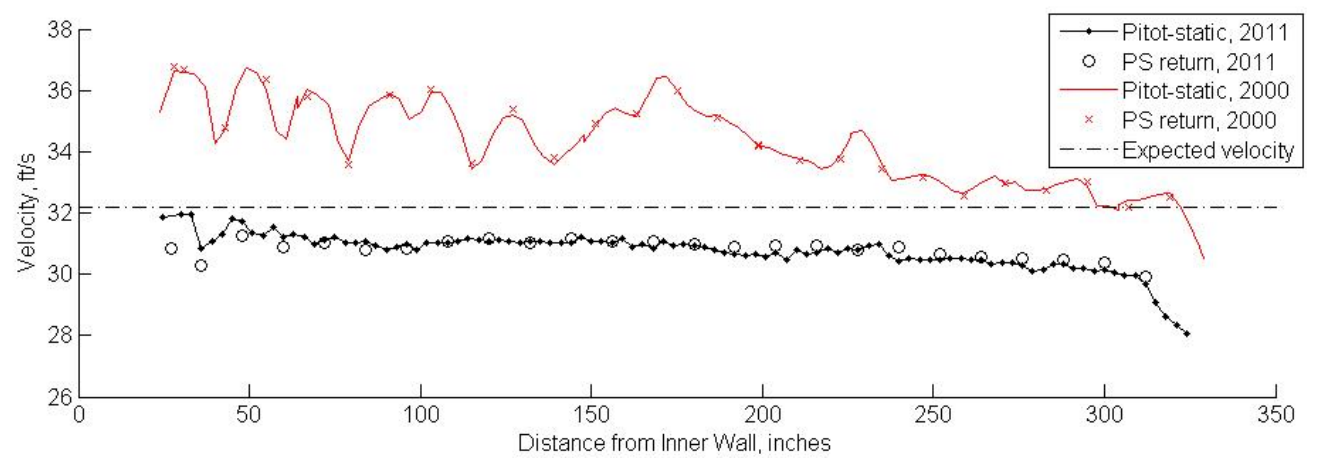

(c) 75.5 inches above the floor

Figure 9: Horizontal Velocity Profiles in the IRT Settling Chamber, comparing the old and new heat exchanger. "PS" designates Pitot-static data, and "return" points were taken on the traversing platform's return path back to its starting point. 


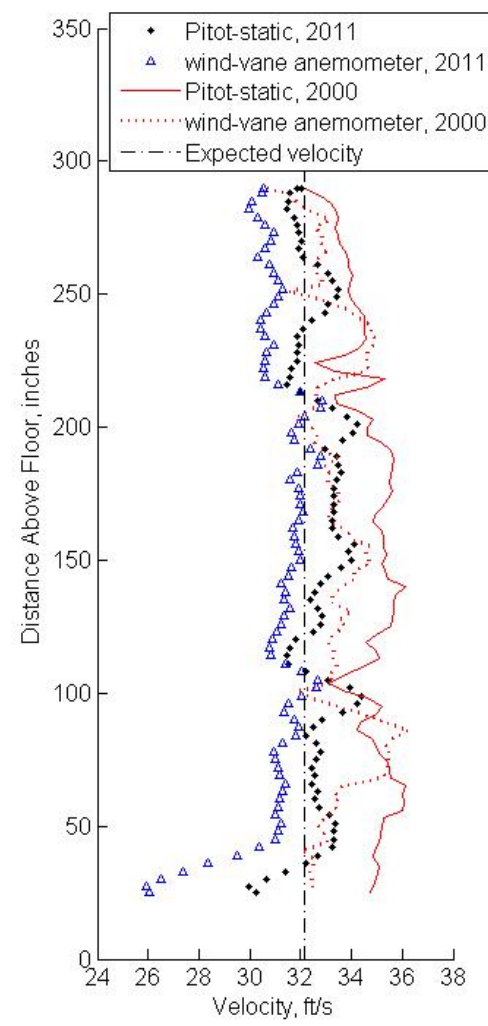

(a) 87.8 inches from Inner wall

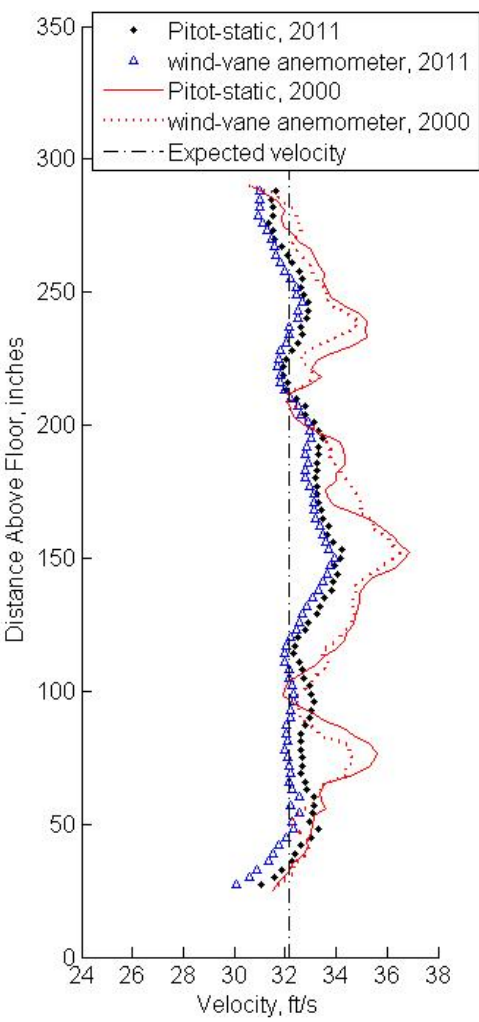

(b) 195.5 inches from Inner wall

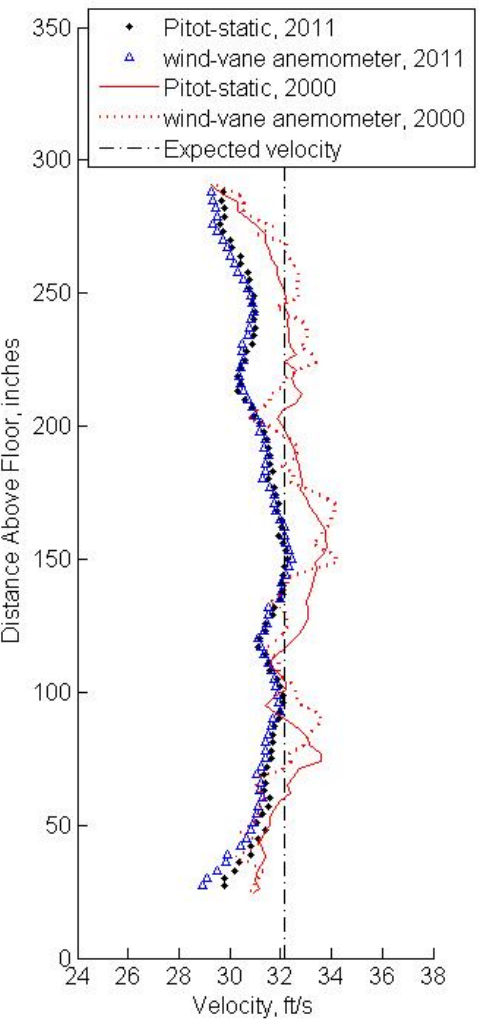

(c) 263.0 inches from inner wall

Figure 10: Vertical Velocity Profiles in the IRT Settling Chamber, comparing the old and new heat exchanger. 


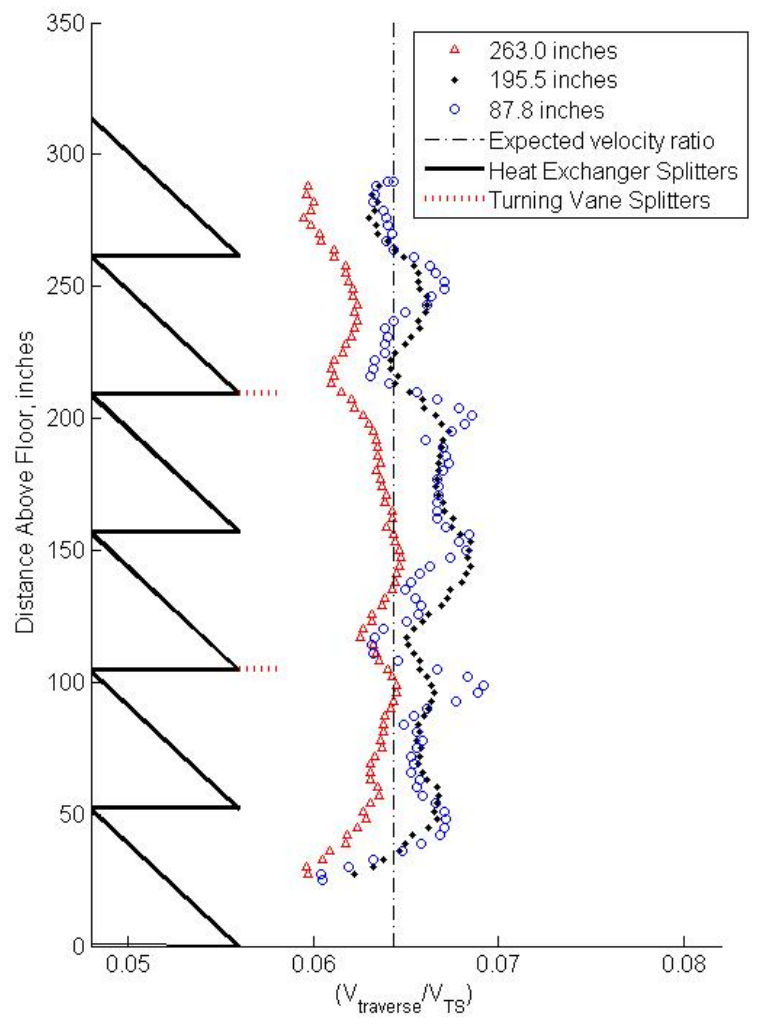

Figure 11: Vertical Pitot-static velocity survey results from the new heat exchanger, normalized by the test section velocity. Physical heights of the heat exchanger splitter planes and turning vane splitter planes are also included. Legend indicates the traversing platform's distance from the inner wall.

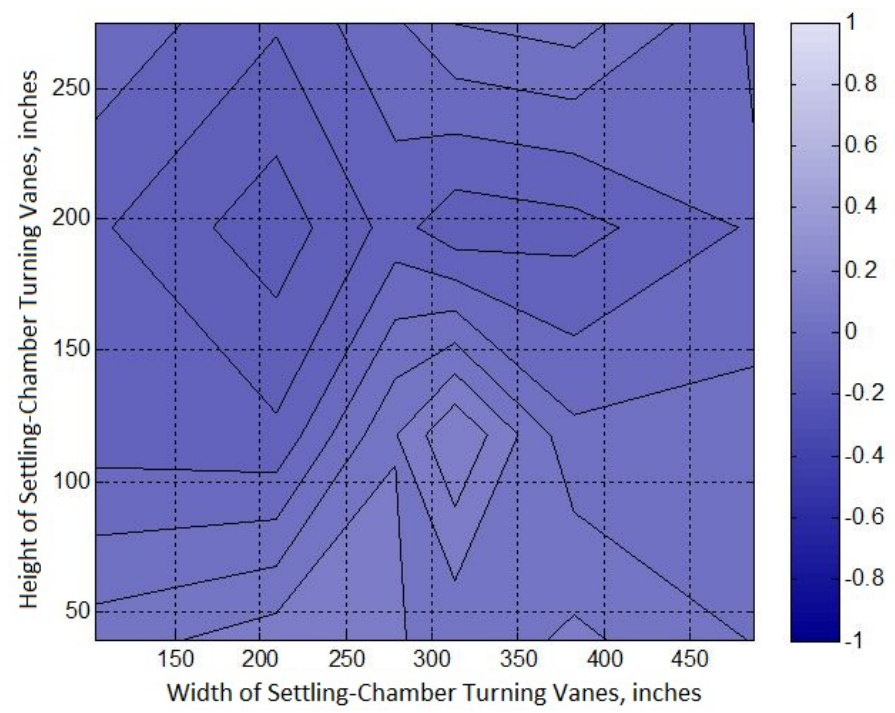

Figure 12: Temperature measurements from the 24 RTDs mounted on the settling-chamber turning vanes. The plot shows the temperature differences $\left(\right.$ in $\left.{ }^{\circ} \mathrm{C}\right)$ between each RTD and the average of all the RTDs $\left(T_{T}-T_{T V}\right)$. Conditions were $U=295 \mathrm{knots}, T_{T V}=6^{\circ} \mathrm{C}$, and spray-bar air off. The average temperature was $6.27^{\circ} \mathrm{C}$, and the values on this plot all lie between $-0.18^{\circ} \mathrm{C}$ and $0.20^{\circ} \mathrm{C}$. 


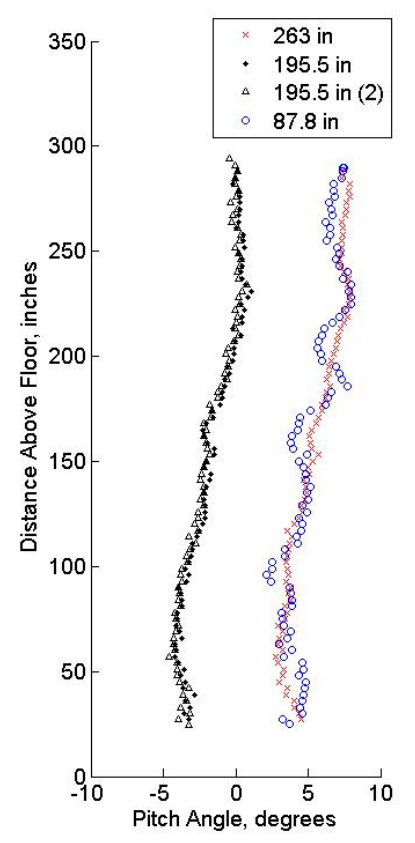

(a) 2011 Pitch Angle

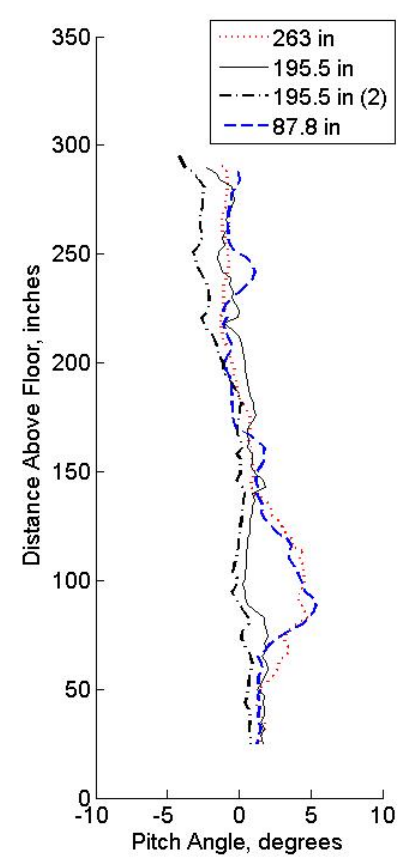

(c) 2000 Pitch Angle

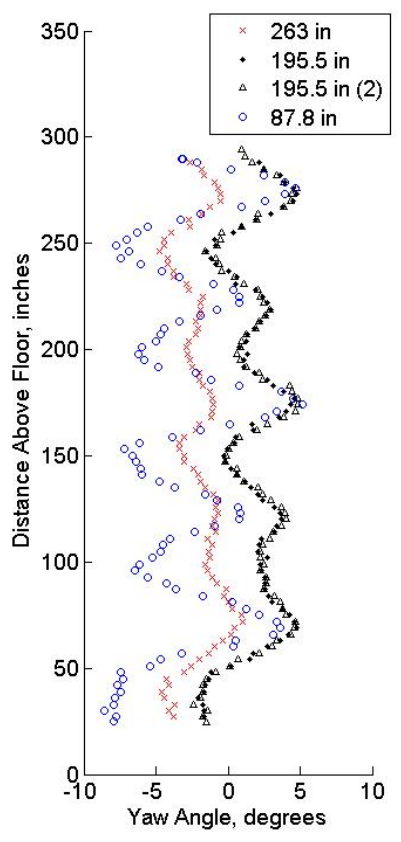

(b) 2011 Yaw Angle

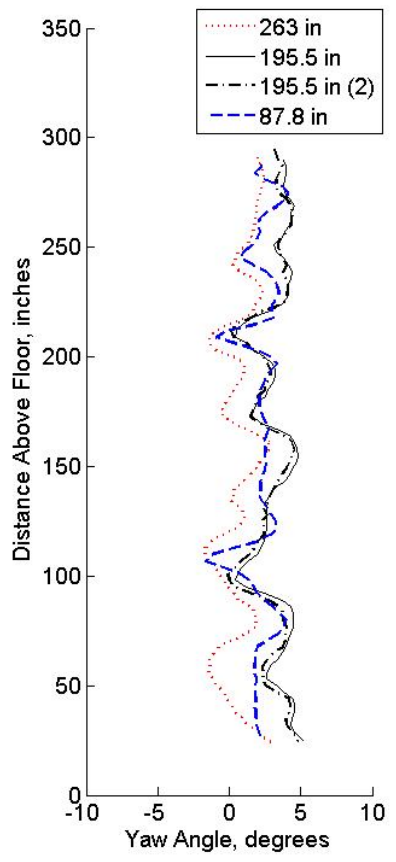

(d) 2000 Yaw Angle

Figure 13: Vertical Flow-Angle Profiles in the IRT Settling Chamber, comparing the old and new heat exchangers. Due to the clearly offsetted nature of the data (especially 2011), these plots are meant to be used for trend identification only, not quantitative values. Legend indicates the traversing platform's distance from the inner wall. The (2) indicates the repeat survey for the centerline traverse. 


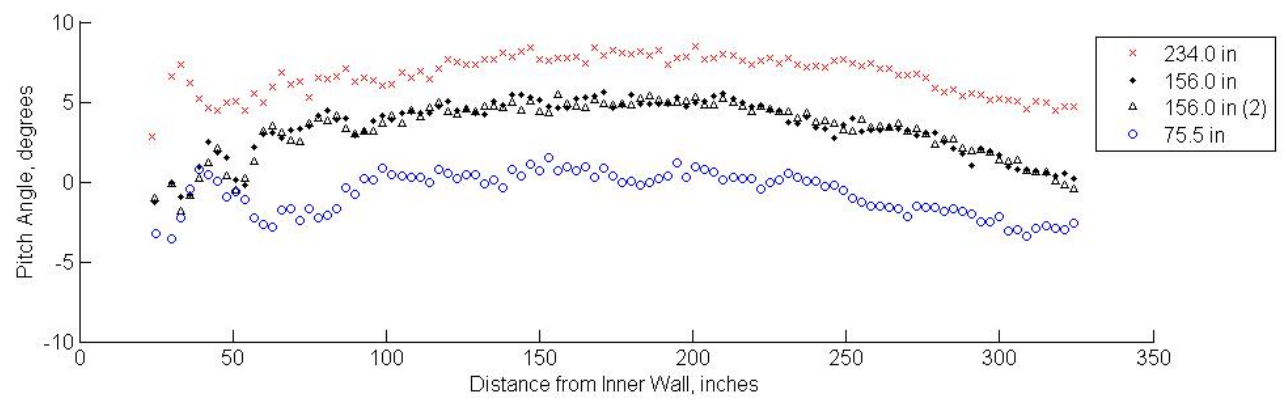

(a) 2011 Pitch Angle

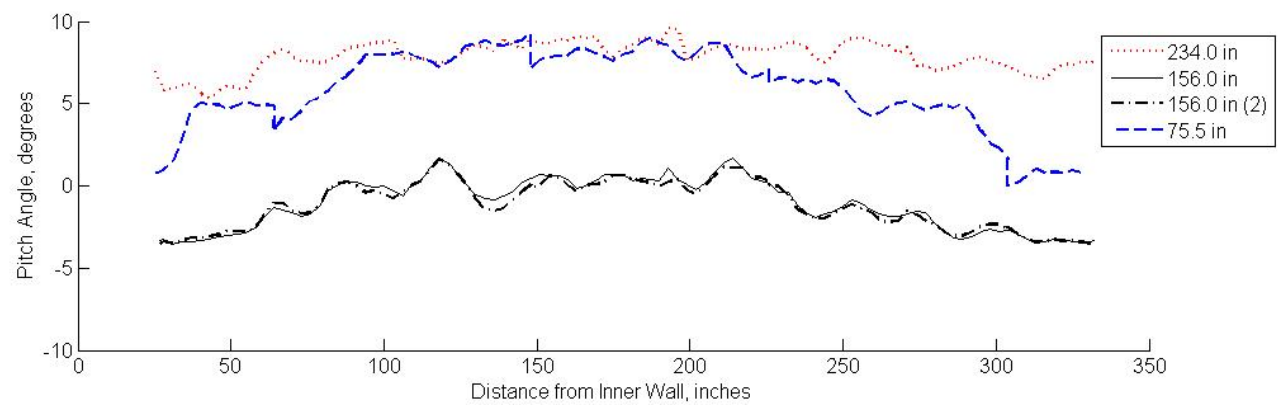

(b) 2000 Pitch Angle

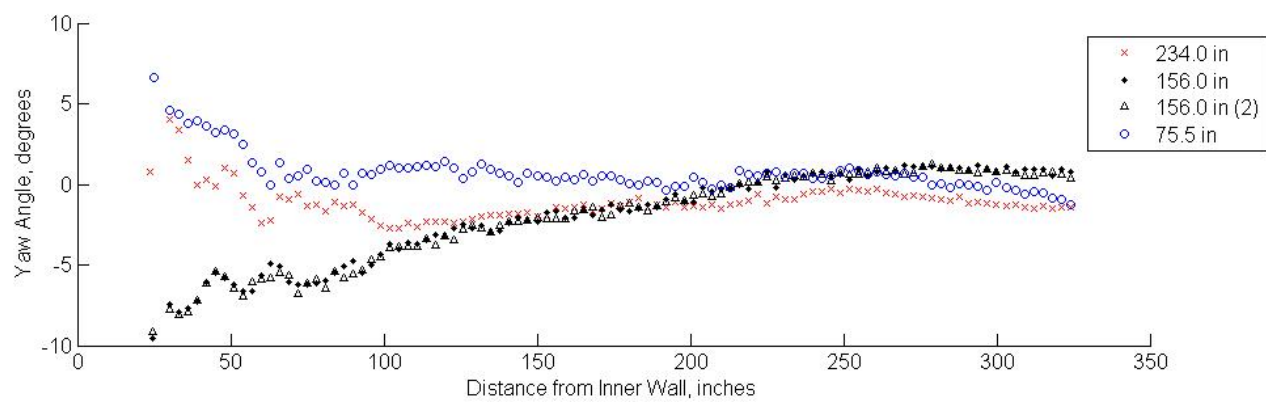

(c) 2011 Yaw Angle

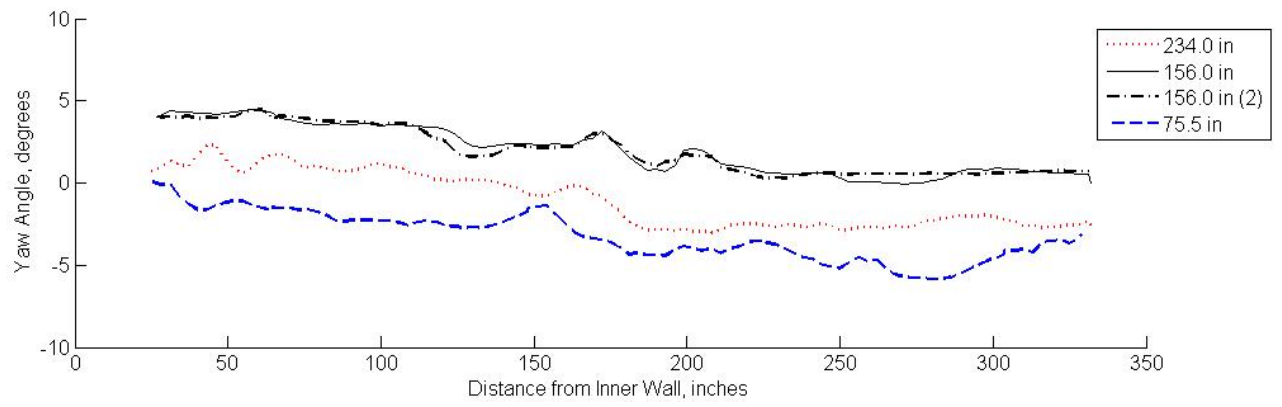

(d) 2000 Yaw Angle

Figure 14: Horizontal Flow-Angle Profiles in the IRT Settling Chamber, comparing the old and new heat exchangers. Due to the offsetted nature of the data seen in the vertical surveys, these plots are meant to be used for trend identification only, not quantitative values. Legend indicates the traversing platform's distance above the floor. The (2) indicates the repeat survey for the centerline traverse. 


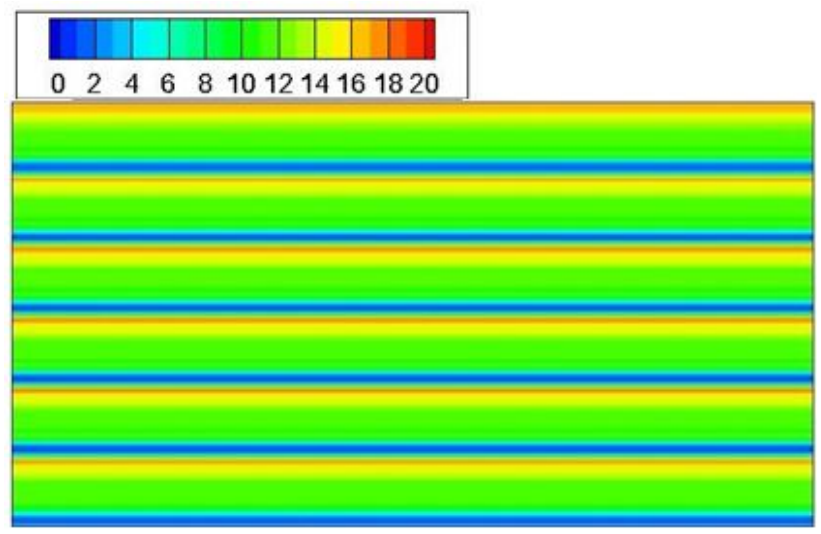

Figure 15: Velocity magnitude contours $(\mathrm{ft} / \mathrm{s})$ at the exit of the 2012 heat exchanger. Figure taken from reference [4] with permission from Clark.
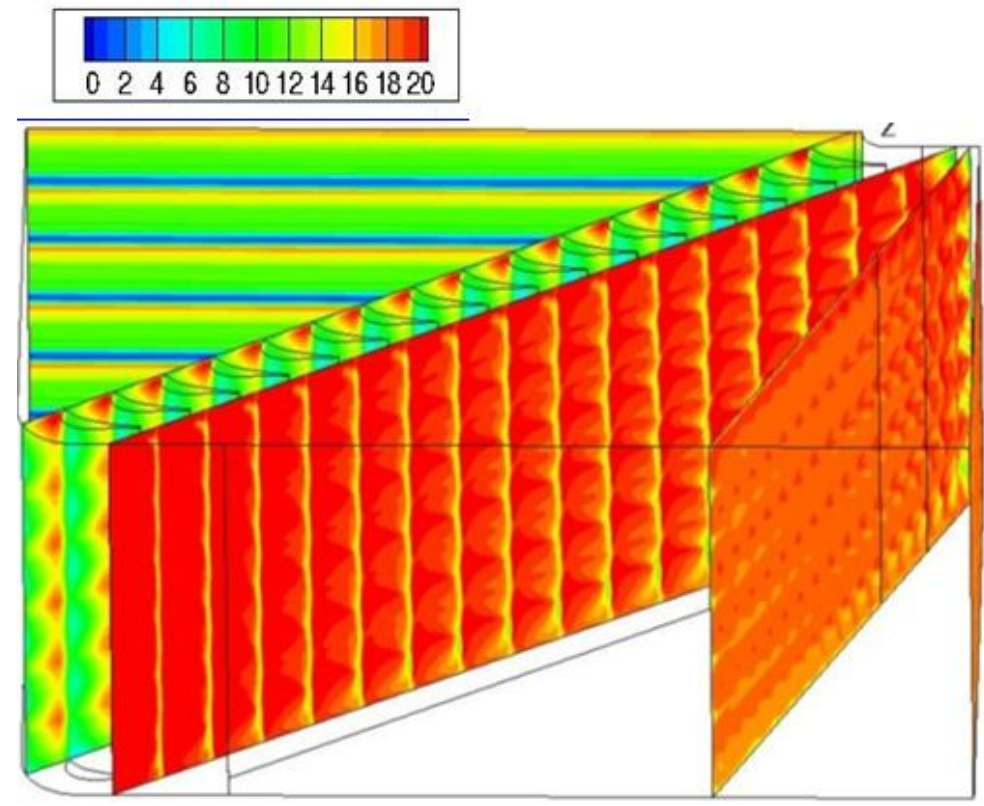

Figure 16: Velocity contours slices (ft/s) in the 2012 IRT settling chamber, from heat exchanger exit, around turning vanes, and into settling-chamber survey plane. Figure taken from reference [4] with permission from Clark. 

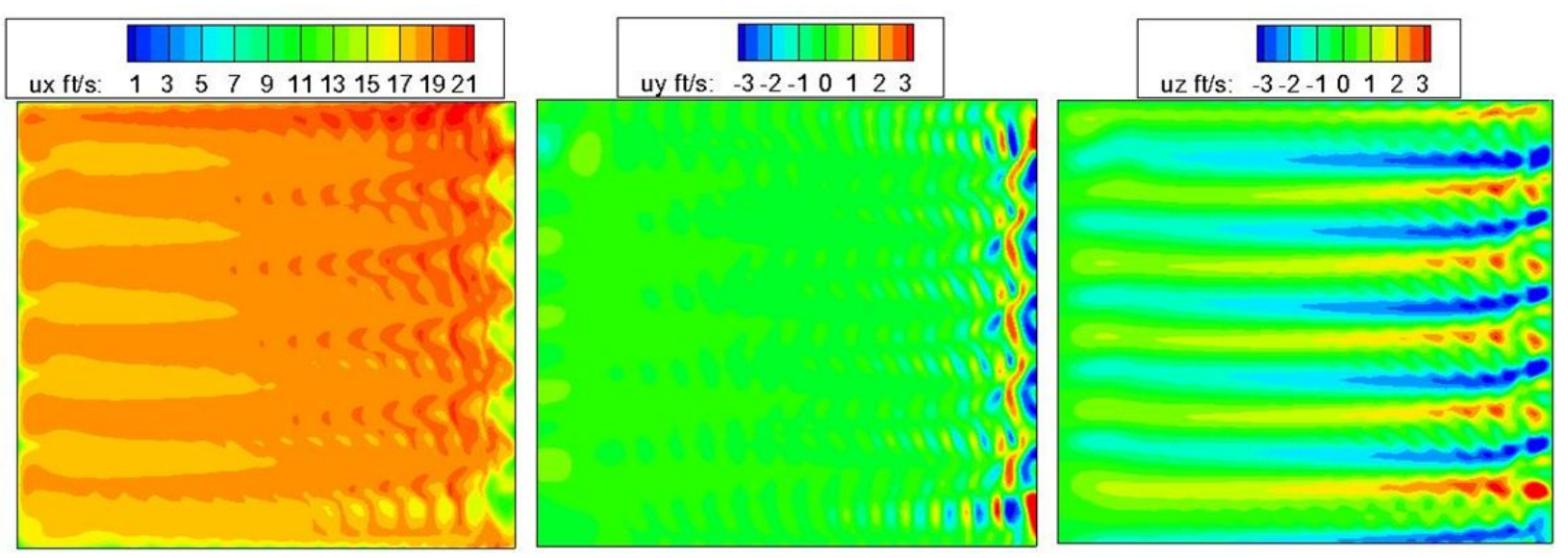

Figure 17: Velocities taken upstream of the spraybars in the settling chamber. These contours are viewed looking upstream, i.e., the right side side is the inside wall of the tunnel. Positive z-velocity is moving to the left. Figure generated by Clark [4] and used with his permission.
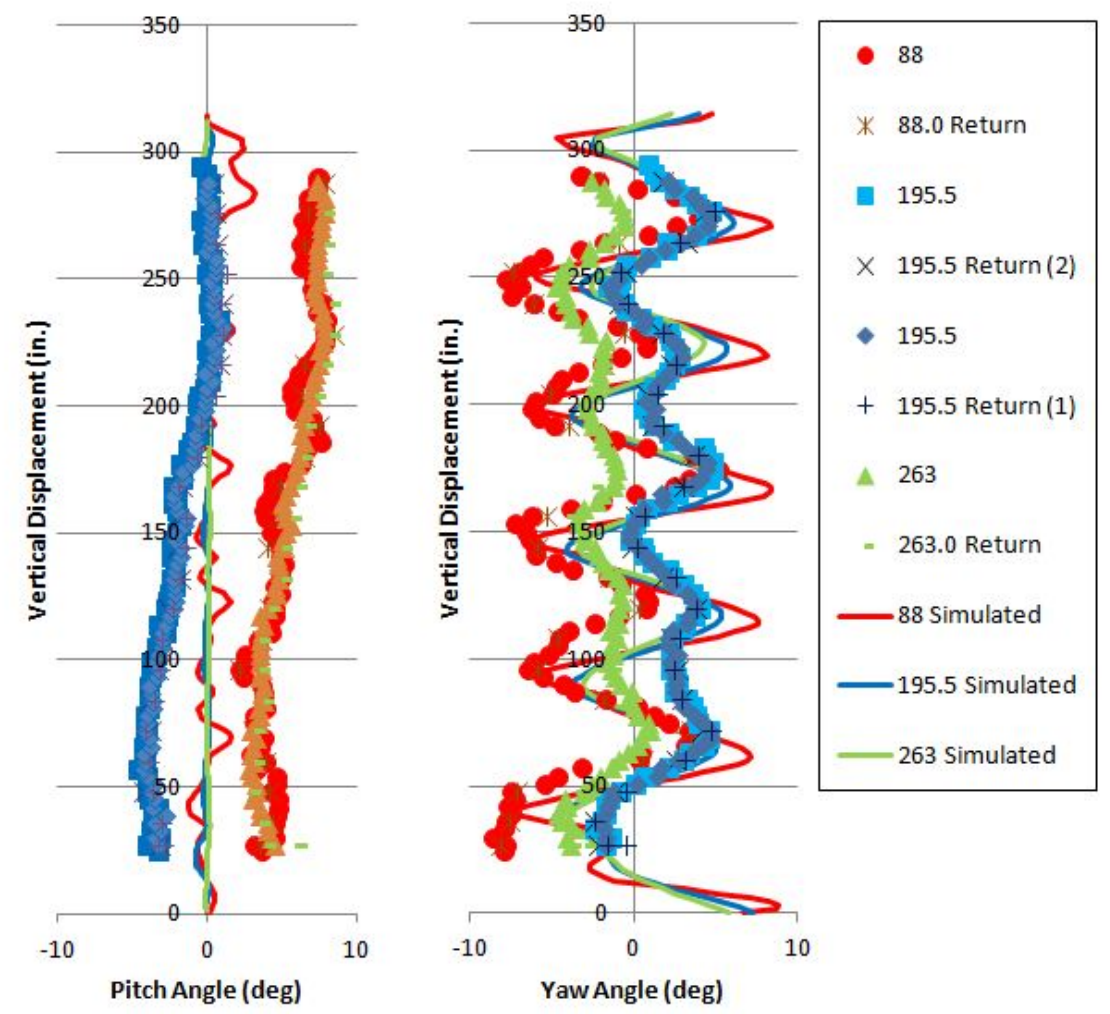

Figure 18: Pitch and yaw angle comparisons between experimental and simulated results. The legend gives the distance in inches from the inner wall. The (1) and (2) indicate the first and second centerline surveys. Figure generated in collaboration with Clark [4] and used with his permission. 